\title{
Commercial Dog Food Consumption in the Caribbean: A Baseline Study
}

\author{
William J. Fielding \\ The College of The Bahamas ${ }^{1}$ \\ Mark D. Newman \\ Market Solutions LLC
}

\section{ABSTRACT}

Dogs in the Caribbean have been traditionally viewed as low maintenance pets which are fed leftovers from the household. Changes in the lifestyle of Caribbean families have resulted in changes in their eating patterns. These changes can be expected to have consequences for the feeding of dogs, which may require households to switch to commercial dog food. This paper reports the finding of a survey of groups involved with pets and animal welfare in the Caribbean conducted on behalf of the Pet Food Institute, a non-profit industry association. The study examined perspectives on how dogs are fed in the Caribbean and activities conducted to educate pet owners and the public. Use of household scraps and commercial dog food was associated with household income, except in the case of some high income dependent territories. The findings indicate that while many animal welfare groups in the Caribbean provide educational programs, not all of these provide recommendations on feeding pets and so they neglect to provide information on an important aspect of animal welfare.

\section{INTRODUCTION}

The Caribbean region consists of a diverse group of territories which were once colonies of various European countries, most notably France, the United Kingdom, the Netherlands and Spain. Today, this diversity is still reflected in the mixture of sovereign states and dependent territories to be found in the region. While some islands are single territories, others are not, and some territories are themselves archipelagos contained within the archipelagic region. Within the region the diversity of development of the territories is encapsulated by their having human development indices which vary from 47 th in the world in the case of Barbados to 158th in the case of Haiti (United Nations Statistics Division, 2012). Within this context there exists the widely reported problem of inadequate pet care (Fielding \& Ostberg, 2008; Grennan \& Fielding, 2008).

According to Coppinger and Coppinger, (2002) wolves adopted a lifestyle that positioned them to take advantage of the feeding opportunities which occurred when humans started to lead a more sedentary existence. This may have been facilitated when men started eating starchy foods (Axelsson et al., 2013). Consequently, man's relationship with dogs can be viewed as one

\footnotetext{
${ }^{1}$ William J. Fielding, Director of Planning, The College of The Bahamas, P.O. Box N-4912, Nassau, Bahamas. Mark D. Newman, President, Market Solutions LLC, Bethesda, Maryland, 20814 USA, www.marketsolutionsllc.com Corresponding author e-mail: wfielding@cob.edu.bs APA Reference: Fielding, W. J., \& Newman, M. D. (2013). Commercial dog food consumption in the Caribbean: A baseline study. International Journal of Bahamian Studies, 19(1), 46-56. https://doi.org/10.15362/ijbs.v19i1.181
}

○W. J. Fielding \& M. D. Newman, 2013. Journal compilation @The International Journal of Bahamian Studies, 2013 
which hinges on humans feeding dogs, directly or through leftovers. Therefore, it is understandable that dogs in the Caribbean have traditionally been fed left-over food from human meals. This link has been manifested in the names which dogs have been given in various parts of the Caribbean. For example, rice dog in Guyana (which is known for its rice growing), pothounds in Trinidad \& Tobago and potcakes in The Bahamas potcake is the name given to the burnt food which gets encrusted on the bottom of a cooking pot (Fielding, 2007). This illustrates the link between the diet of dogs and that of humans. Consequently, changes in the human diet and eating habits can be expected to have an impact on the diet of dogs.

According to one report published about consumption of food by humans in the Caribbean: "More and more Caribbean families are eating foods away from their homes in the form of 'fast foods', snacks and carbonated drinks" (Caribbean Food and Nutrition Institute, Pan American Health Organization, \& World Health Organization, 2004, p. 25). These foods appear to be displacing the traditional staples of the Caribbean diet (Inter-American Institute for Cooperation on Agriculture, 2009). Therefore, as families prepare fewer meals at home the opportunities for dogs to be fed leftovers diminish. This raises the question as to what households should now give to their pets to eat. One solution would be commercial pet food. Consequently, as humans turn to commercially prepared food for themselves, they may be obliged to follow a similar route for their pets.

The change in human eating habits becomes of greater importance in communities where mixed-breed or mongrel dogs are considered to be low maintenance and not pets on which owners would expect to spend money (Fielding, Mather, \& Isaacs, 2005). The feeding of home-made food or table scraps to dogs, food which would otherwise be thrown away, would be a low-cost way of feeding the family dog. In Jamaica, one cost saving measure used when feeding dogs included giving dogs pig feed rather than more expensive dog food (Williams, 2012). This unintended consequence of government import and tax policies that often make pet food more expensive than animal feeds in the region has a number of potential disadvantages. Livestock feeds would not be expected to offer the appropriate nutrient balance for dogs. Also, some livestock feeds may be potentially dangerous for dogs depending upon the additives used (Yaeger, Mullin, Ensley, Ware, \& Slavin, 2012). The nutritional value of the traditional diets fed dogs in the Caribbean appears to be unknown, but could be expected to be variable. Reports by early visitors to the Caribbean paint a picture of starving dogs (e.g., Fielding et al., 2005) but it is not clear if their diet was limited in quantity, quality or both. What is clear is that historically, food appropriate for dogs could be difficult to purchase (Fielding et al., 2005) which may indicate a longstanding lack of demand and/or supply sources. Today, it is appreciated that nutrition is an important element in the care and welfare of dogs, as for any animal. Pet food formulation has become scientifically based (National Research Council, 2006) and manufacturers acknowledge the importance of the nutritional aspects of their products through their research divisions and research on dietary requirements of specific populations of dogs, for example, http://www.petfoodinstitute.org/?page=Sound Nutrition.

Although concern with animal welfare has a long history in some parts of the Caribbean (e.g., starting in the 1890s in the case of The Bahamas, Fielding et al., 2005), only comparatively recently has animal welfare received regional prominence, in part due to a 
series of Caribbean animal welfare conferences, which first started in 2002 (Humane Society International, 2002). Such gatherings have shown that a number of organizations are involved in addressing animal welfare throughout the Caribbean region and that they have noted much change in the care of companionable animals, even if the level of care still remains a cause for concern. However, the limited resources of these organizations constrain their activities, which tend to focus on neutering dogs and cats. Despite these limitations, animal welfare groups have seen improvements in pet care in recent years (Fielding \& Ostberg, 2008).

To date, there appears to be little information on the diets of dogs in the Caribbean. The FAO's Dog Population Management Options with Special Emphasis on Animal Welfare and Health (2010) contains little on dog nutrition, other than referring to sources of scraps which may help to maintain the dog populations. One study from New Providence, The Bahamas did ask about the feeding of commercial dog food (Fielding, 2007). That study found that $56 \%$ of dogs were fed only commercial food, but the type of dog was linked to the likelihood that the dog was fed commercial food. For example, 39\% of local mixed-breeds were fed only commercial dog food as opposed to $65 \%$ of pure-breed dogs. While overall $31 \%$ of dogs were fed only table scraps, $37 \%$ of local mixed-breeds were fed only table scraps compared to $7 \%$ of purebreed dogs.

In the light of the changing feeding patterns of humans, commercial dog food may be the only reliable way in which dog owners can appropriately feed their dogs. Therefore, this paper seeks to examine current feeding practices of dog owners in order to provide baseline information in what is probably a dynamic context.

\section{METHOD}

An Internet-based survey was designed by the authors covered a range of issues associated with animal welfare and commercial pet food, for cats and dogs as part of a Market Solutions LLC study conducted on behalf of the Pet Food Institute, a non-profit industry association (Pet Food Institute, 2013). A study by Fielding and Ostberg (2008) was taken as the starting point for the new survey. The range of questions was expanded to gather data on the perceived use of commercial pet food. A summary of the survey questions is given in Table 1 , but this paper does not attempt to report all the survey findings.

Table 1

Summary of the full set of questions on the survey form

Territory to which information relates

Activities undertaken and types of animals targeted, by the organization with which respondent is affiliated

Methods of communication of organization to its constituents

Animal related events put on by the organization

Usefulness of various methods of educating the public

Information on collaboration and sponsorship

Respondent choice of best food for cats \& dogs

Estimate of the \% of cats \& dogs given various diets

Organizational recommendation of best food for cats \& dogs

Places selling pet food

Preference for origin of commercial food

Estimates of the numbers of cats \& dogs

Information on pet care

Information on stray dogs

The Internet link to the survey was sent to participants of the 2011 and 2008 Caribbean Animal Welfare Conferences and selected others, including kennels and those who provided veterinary services. Therefore, the 
target population was those people who were active in animal welfare and so presumed knowledgeable about animal welfare issues in their territory. The survey was sent out in English as it was assumed that the target population had fluency in English as this group had attended these English-speaking conferences. The methodology of consulting animal welfare experts on animal welfare issues has been used by international animal welfare groups (e.g., Tasker, 2007; Batson, 2008) in order to obtain information from multiple countries. Replies from respondents who were not residents of the Caribbean were excluded from the data analysis. Potential participants were invited to take part in a prize draw for a gift token as an incentive to respond.

In The Bahamas and Jamaica, a range of locations (super markets, corner shops, pet shops, animal welfare groups, veterinary clinics) were visited to get information on the pet food for sale (if any). The project also involved interviews and collection of ancillary information in other territories that is reported elsewhere (Market Solutions LLC, 2012).

\section{RESULTS}

A total of 59 responses were included in the analysis. These respondents represented 21 territories from the Caribbean and are listed in Table 2.

Table 2

List of territories covered in the study.

\begin{tabular}{ll}
\hline Anguilla & Martinique \\
Antigua \& Barbuda & Puerto Rico \\
Aruba & Saba \\
Barbados & St Martin/St Maarten \\
Belize & St. Kitts \& Nevis \\
British Virgin Islands & Suriname \\
Cayman Islands & The Bahamas \\
Dominica & Trinidad \& Tobago \\
Dominican Republic & Turks \& Caicos \\
Grenada & U.S. Virgin Islands \\
Jamaica &
\end{tabular}

The most common activities performed by agencies with which respondents were affiliated were providing animal sheltering services, pet adoption, neutering programs and animal welfare education programs (Table 3). Relatively few of the agencies sold products for animals (those who did were located in Dominican Republic, and The Bahamas).

Table 3

Activities performed by agencies to which respondents were affiliated

\begin{tabular}{lc}
\hline Activity & $\%$ \\
\hline Spay / Neuter program & $71 \%$ \\
Animal welfare education program & $66 \%$ \\
Animal shelter & $53 \%$ \\
Pet adoption agency & $47 \%$ \\
$\begin{array}{l}\text { Animal welfare policy advocacy related to } \\
\text { dogs and/or cats }\end{array}$ & $41 \%$ \\
Veterinary clinic & $24 \%$ \\
Animal welfare policy advocacy related to & \\
livestock and/or wild animals & $19 \%$ \\
Boarding kennel & $17 \%$ \\
Law enforcement & $12 \%$ \\
Government department & $7 \%$ \\
Retailer of products for animals & $5 \%$ \\
\hline Total & 59 \\
\hline
\end{tabular}

Respondents personally thought that commercial dog food should be the choice of food for cats and dogs (Table 4). However, many respondents thought that table scraps should also be included in the pet's diet. It should also be noted that respondents from within the same territory did not always agree as to what the best feeding practice should be. When only respondents whose organization had an animal welfare education program are considered, individuals are even more likely to promote a mixture of table scraps and commercial food. 
Table 4

Personal attitudes of respondents about the best choice for feeding pet cats and dogs.

\begin{tabular}{|c|c|c|c|c|}
\hline & $\begin{array}{l}\text { A mixture of commercial food and } \\
\text { table scraps or home prepared } \\
\text { food }\end{array}$ & $\begin{array}{l}\text { Commercial or } \\
\text { store bought } \\
\text { food }\end{array}$ & $\begin{array}{l}\text { Human food prepared } \\
\text { specifically for their } \\
\text { pet(s) }\end{array}$ & Total \\
\hline$\%$ of respondents & $43 \%$ & $47 \%$ & $9 \%$ & 53 \\
\hline $\begin{array}{l}\% \text { of respondents when organization } \\
\text { had an animal welfare programme* }\end{array}$ & $60 \%$ & $31 \%$ & $9 \%$ & 35 \\
\hline
\end{tabular}

Just over half of the respondents indicated that their organization recommended commercial food for pets. In general, homemade pet food was not often recommended, but a combination of commercial and home foods or table scraps was the second most commonly recommended food source; leftover human food was never recommended. However, not all respondents indicated that their organization made recommendations on pet nutrition (Table 5). In the case of respondents associated with organizations which had animal welfare education programs, about 20\% did not make recommendations on pet feeding and nutrition. Some respondents indicated that their recommendations had to take into account the availability of commercial food (some said that "availability of commercial diets in rural areas very poor") and cost ("economic restrictions").

\section{Table 5}

Organizational recommendations for feeding cats and dogs focused on commercial pet food

\begin{tabular}{|c|c|c|c|c|c|c|}
\hline & $\begin{array}{l}\text { Left-over } \\
\text { human food or } \\
\text { table scraps as } \\
\text { their primary } \\
\text { food }\end{array}$ & $\begin{array}{l}\text { Human food } \\
\text { prepared } \\
\text { specifically for } \\
\text { pet(s) }\end{array}$ & $\begin{array}{l}\text { Commercial } \\
\text { or store } \\
\text { bought food }\end{array}$ & $\begin{array}{l}\text { A mixture of } \\
\text { commercial food and } \\
\text { table scraps or home } \\
\text { prepared food }\end{array}$ & $\begin{array}{l}\text { Does not make } \\
\text { recommendations } \\
\text { on pet nutrition }\end{array}$ & Total \\
\hline$\%$ of respondents & $0 \%$ & $3 . \%$ & $52 \%$ & $29 \%$ & $16 \%$ & 62 \\
\hline $\begin{array}{l}\% \text { of respondents } \\
\text { when organization } \\
\text { had an animal } \\
\text { welfare program }\end{array}$ & $0 \%$ & $5 \%$ & $49 \%$ & $33 \%$ & $21 \%$ & 39 \\
\hline
\end{tabular}

Note. Multiple responses were allowed, so the total number of responses exceeds 59.

The practice of feeding left-over human food appears to still be common in many territories, and was reported as the most common food source in 13 of the 21 territories, see Table 6; this is despite the recommendations noted in Table 5. In only four territories (Antigua \& Barbuda, Aruba, Martinique, and The Bahamas) was commercial dog food the most common food source.

Table 6

Estimated median percentage of dogs given food of different types.

\begin{tabular}{ccccc}
\hline & $\begin{array}{l}\text { Feed human table food } \\
\text { scraps as their primary food }\end{array}$ & $\begin{array}{l}\text { Human food prepared for } \\
\text { the dogs }\end{array}$ & $\begin{array}{l}\text { Commercial or store } \\
\text { bought food }\end{array}$ & $\begin{array}{l}\text { A mixture of commercial and table } \\
\text { scraps or home prepared food }\end{array}$ \\
\hline Median & 45.5 & 8.2 & 34.0 & 27.0 \\
\hline
\end{tabular}


Supermarkets were the most likely places from where residents could buy commercial pet food. Relatively few veterinary clinics and animal welfare groups were reported as selling pet food (Table 7). In The Bahamas, Jamaica and Trinidad, it was observed that dog food could be bought in bulk, but also that large bags were broken open so that smaller amounts could be bought. Respondents from only three territories (Belize, Barbados and the Dominican Republic) indicated that pet food was manufactured within the territory. Otherwise manufactured pet food was always imported.

Table 7

Locations (percentage of all territories) from which residents purchase commercial pet food.

\begin{tabular}{cccccccc}
\hline $\begin{array}{l}\text { Supermarket } \\
\text { chain }\end{array}$ & Pet store & $\begin{array}{l}\text { Corner } \\
\text { store }\end{array}$ & $\begin{array}{l}\text { Private } \\
\text { veterinary } \\
\text { clinic }\end{array}$ & $\begin{array}{l}\text { Animal welfare } \\
\text { group }\end{array}$ & $\begin{array}{l}\text { On-line or via the } \\
\text { Internet }\end{array}$ & $\begin{array}{l}\text { Other } \\
\text { from territory }\end{array}$ \\
\hline $83 \%$ & $56 \%$ & $49 \%$ & $47 \%$ & $8 \%$ & $5 \%$ & $10 \%$ & 59 \\
\hline
\end{tabular}

All territories reported an improvement in the nutritional aspect of animal welfare in the last five years, on a scale of 1 to 5 , (from use of nutritious food is much worse to very much improved) the mean response was 3.6 ( $S E=$ .129). Only four of the 51 respondents thought that the nutritional aspect of animal welfare had become worse in the last five years.

As indicated in the introduction, the territories exhibit marked differences. Analysis of average household income and the use of leftover human food as the primary source of dog food indicates a lack of a relationship between the two, as seen in Figure 1.

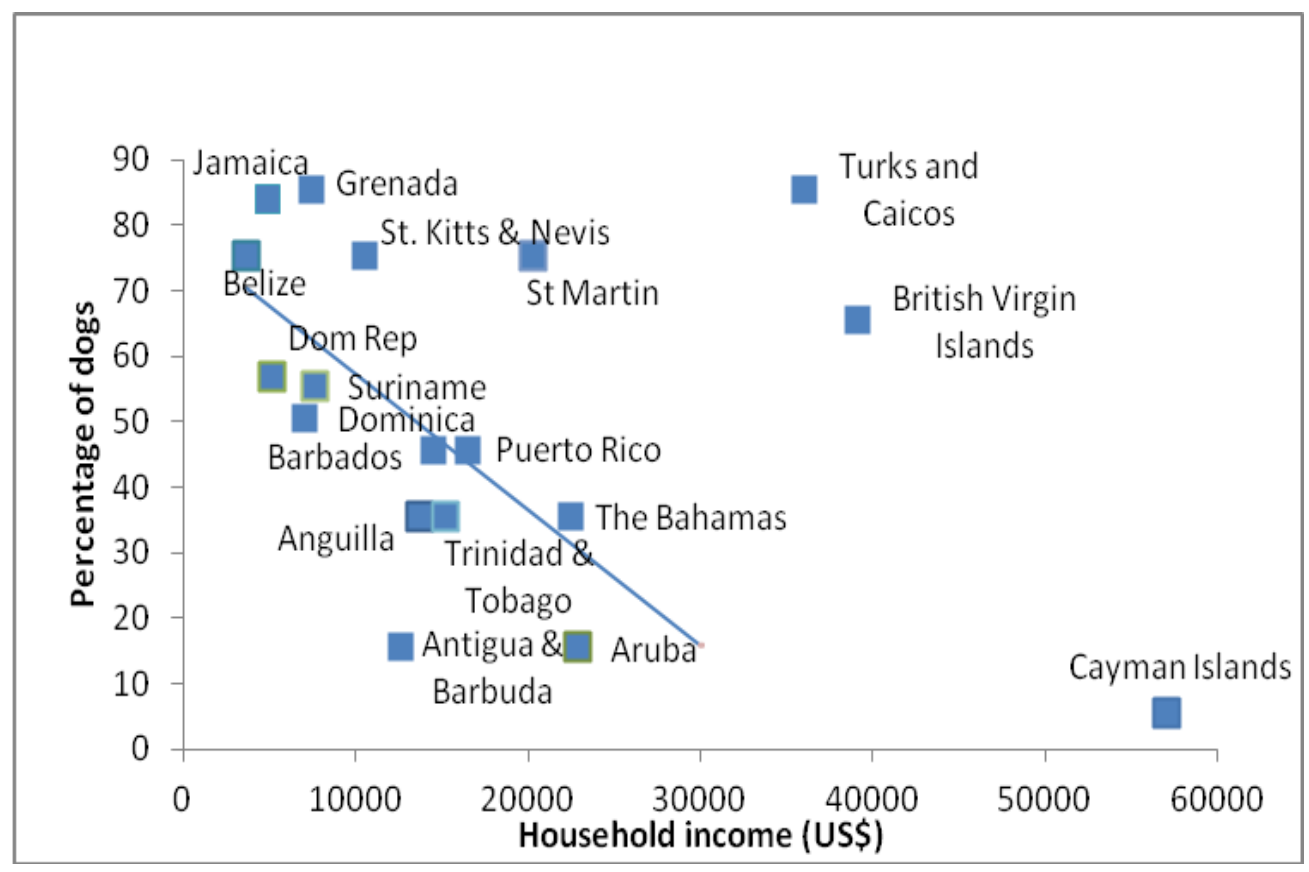

Figure 1. The relationship between household income and percentage of dogs fed household scraps as their primary source of food. (Linear regression line for territories excluding Turks \& Caicos, British Virgin Islands and Cayman Islands. 
Further, no link was seen between the percentage of dogs fed commercial food and household income, as illustrated in Figure 2.

However, the territories with the highest household incomes greatly influence the associations. Once the Turks \& Caicos Islands, the British Virgin Islands, and the Cayman Islands are omitted, the expected relationships between income and the feeding of commercial food, a positive relationship, and scraps, a negative relationship, were discerned (Table 8). However, it should be noted that in the case of commercial dog food, the relationship still fails to meet formal statistical significance, possibly due to the small sample size. Nonetheless, based on linear regression results, income level alone explains almost twice as much of the decline in feeding table scraps $(33 \%)$ as it does the increase in feeding commercial pet food (18\%). This supports the potential value of nutrition education and other factors that remain to be identified in improving dog nutrition.

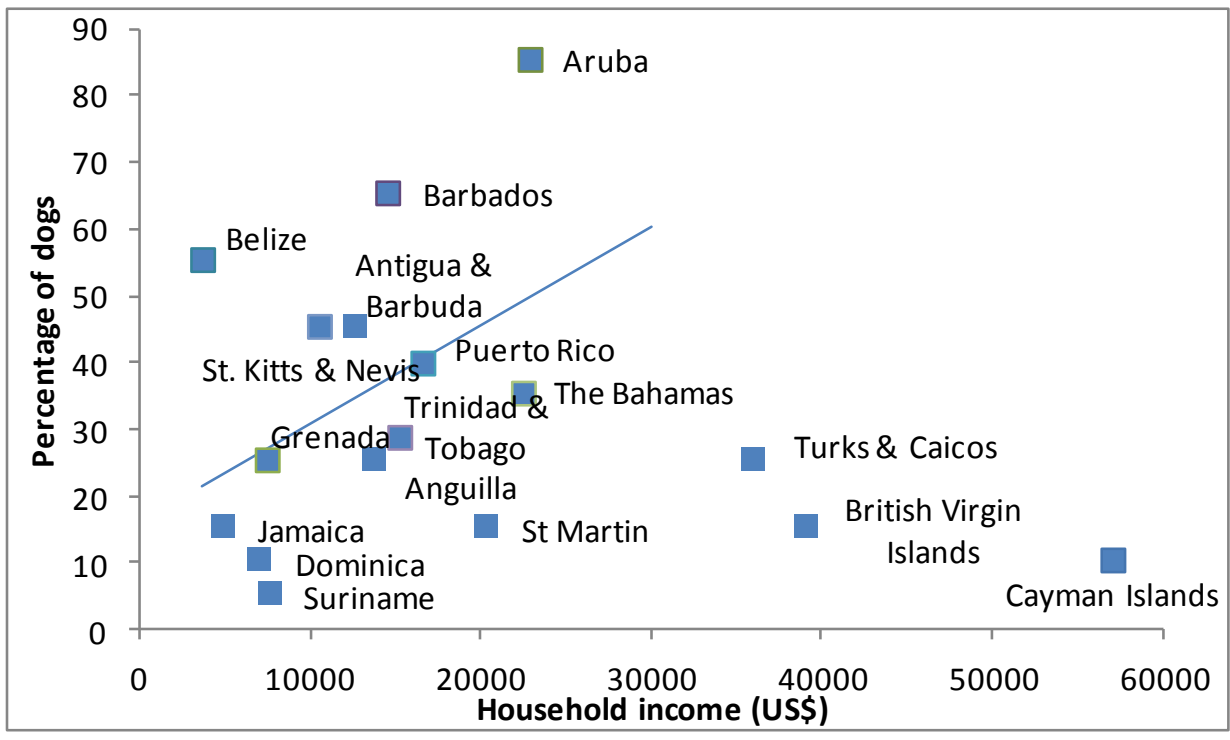

Figure 2: The relationship between household income and percentage of dogs fed commercial food as their primary source of food. (Linear regression line for territories excluding Turks \& Caicos, British Virgin Islands and Cayman Islands.

Table 8

Pearson correlation coefficient ( $r$ ) between household income and the estimated percentage of dogs fed food from four sources.

Correlations with household income

\begin{tabular}{|c|c|c|c|c|c|c|}
\hline & & Scraps & Homemade food & Commercial & Scraps \& commercial\$ & \\
\hline \multirow{3}{*}{ All territories } & $r$ & -.36 & $.50^{*}$ & -.13 & $.47^{*}$ & $N=18$ \\
\hline & & & & & & \\
\hline & $p=$ & .075 & .017 & .306 & .045 & \\
\hline \multirow{2}{*}{$\begin{array}{l}\text { Turks \& Caicos Islands, British Virgin } \\
\text { Islands, and the Cayman Islands omitted }\end{array}$} & $r$ & $-.57^{\star}$ & -.15 & .42 & .15 & $n=15$ \\
\hline & $p=$ & .013 & .150 & .059 & .315 & \\
\hline
\end{tabular}

$\S n=16$ and 13 for associations with Mixed.

${ }^{*}$ Indicate $p<.05$, single tailed test

Note: For some territories average household income was unavailable. 


\section{DISCUSSION}

The data collected in this study represent the expert opinions of persons who should be well acquainted with animal welfare issues in their territory. However, where studies have been done, the opinions of local animal experts have not always been verified (e.g., Fielding et al., 2005; Fielding, Gall, Green, \& Eller, 2012), so we advise some caution when interpreting the figures. However, until such time as more detailed research studies are undertaken in each territory, the current methodology may be the best available.

As noted in the introduction, the territories of the Caribbean are diverse. However, as far as the activities of the organizations represented by the participants are concerned, these focused on a limited number of activities: animal sheltering, pet adoption, neutering and animal welfare education programs. Consequently, it would be expected that the nutritional aspect of animal welfare would have improved in recent years as it is anticipated that nutrition would have been covered in their animal welfare education programs.

Although the fact that most respondents thought that pet nutrition had improved may be linked with animal welfare education, it was still found that only half of all groups recommended commercial dog food alone, and one in five groups offering animal welfare education did not make any recommendations at all on feeding and nutrition. As a result, the research results did not offer clear findings on the contribution of animal welfare education to perceptions of improved animal nutrition or the extent to which local circumstances affect how pet owners and caregivers feed dogs.

The findings suggest that animal welfare groups could do more to teach pet owners about pet nutrition and feeding and this would strengthen their animal welfare educational programs. The fact that all territories reported an improvement in pet nutrition is important as it puts the figures in this 2012 study in a context, which despite concerns about pet nutrition which may exist today, suggests that matters would have been of greater concern five years ago. It would be useful for future research to assess the extent to which dog caregivers respond to the recommendation of animal welfare groups, veterinarians, retailers and other sources on pet nutrition.

It might have been anticipated that all the organizations with animal welfare education programs would make recommendations regarding pet food. The fact that this is not so suggests that this is an area of concern as nutrition is an important component of animal welfare. One in five organizations that offered animal welfare education programs did not have an organizational recommendation on feeding pets. It would be anticipated that their recommendations would take into account local practices, history, and the economic situation of caregivers. Given the history of feeding left-over food to dogs, it is not surprising that this practice persists today, particularly in those territories with lower household incomes. This is also consistent with the cultural view in The Bahamas (at least) that one does not spend money on local mixed-breed dogs (Fielding et al., 2005). While organizations may have one recommendation, their workers are entitled to their own opinion. The fact that some respondents' recommendations differed from those of their organizations, even when that organization had an animal welfare education program, confirms the influence of cultural norms, and so in many cases, may reflect a pragmatic need to be responsive to local realities. This may indicate the need for training of all animal welfare workers in the area of nutrition, particularly if the nutritional value of local food is unknown or poor, so that local recommendations are the most 
appropriate for that community. For example, what is the welfare trade-off between a more expensive commercial food which supplies the nutritional needs of the pets and a cheaper homemade diet (human food prepared specifically for the pet) which may not? Respondents also indicated that not all animal welfare stakeholders sold dog food. This omission may represent a lost opportunity to raise funds and might be seen as acting inconsistently with recommendations to caregivers, that is, use commercial dog food. Despite this, commercial dog food was reported as widely, although not universally, available throughout the communities surveyed, primarily from corner stores and supermarkets in all territories.

As noted, in The Bahamas (Fielding, 2007, 2010), feeding practices vary according to the size or type of dog kept. Studies from The Bahamas (Fielding \& Plumridge, 2005) and Dominica (Davis, Alie, Fielding, Morters, \& Galindo, 2007) indicate that while many dogs are mixed-breeds, some dogs are considered breed dogs and so have some monetary value. These dogs are more likely to be fed commercial food than mixed-breeds and so if the population of breed dogs increases, proportionately more dogs may be given commercial dog food. This observation is important as it suggests that as fashions in choice of dog change, this may result in feeding practices which could be beneficial to animal welfare.

While commercial food might be considered as the most convenient means of providing an appropriate diet for pets, as commercial pet food is typically imported, its cost cannot be overlooked. The fact that commercial pet food is generally imported makes its price susceptible to import duties, taxation, exchange rate changes etc., and so risks making pet food prices expensive in local currency. It should be noted that devaluations and currency controls are not uncommon in the region (Worrell, Marshall, \& Smith, 2000). As a result, it had been anticipated that the use of commercial pet food would be linked to average household income. No such link was observed between household income and the feeding of scraps or commercial food until the Turks \& Caicos Islands, British Virgin Islands, and the Cayman Islands were omitted. While it is not immediately clear why these territories do not appear to conform to the pattern of the other territories, the similarities of this group of three are striking. Each of these territories shares a similar British colonial background, even to the extent of still being dependencies of the United Kingdom. Also, they are well known for their high cost of living, so despite their higher household incomes, caregivers may still be deterred from providing commercial food for dogs.

Overall, the linkage between income and the feeding of commercial pet food indicates that this is a price-sensitive item, which combined with the reluctance of caregivers to spend money on mixed-breed dogs probably contribute to a resistance to buy dog food. Even in a relatively wealthy country such as The Bahamas, dog food still needed to be sold in smaller amounts than that packaged by the manufacturers in response to the economic constraints of caregivers. However, as household incomes increase, provided cultural attitudes towards feeding dogs scraps can be modified, a greater percentage of dogs can be expected to be fed commercial food. As indicated previously, the move towards feeding commercial food may be accelerated in response to the changing eating patterns of households and the effect this has on the availability of scraps for dogs.

Therefore, this study provides a baseline for assessing changes in the types of food offered dogs as humans continue to alter their eating habits and animal welfare groups continue to educate pet owners on animal welfare. 


\section{REFERENCES}

Axelsson, E., Ratnakumar, A., Arendt, M., Maqbool, K., Webster, M. T., Perloski, M., Liberg, O., Arnemo, J. M., Hedhammar, A., \& Lindblad-Toh, K., (2013, March 21). The genomic signature of dog domestication reveals adaptation to a starch-rich diet [Letter to the Editor]. Nature, 496, 360-364.

doi:10.1038/nature11837

Batson, A. (2008). Global companion animal ownership and trade: Project summary, June 2008. Retrieved from World Society for the Protection of Animals website www.wspa-international.org

Caribbean Food and Nutrition Institute, Pan American Health Organization, \& World Health Organization. (2004). Uses of food consumption and anthropometric surveys in the Caribbean: How to transform data into decision-making tools. Rome, Italy: Food and Agriculture Organization of the United Nations. Retrieved from ftp://ftp.fao.org/docrep/fao/008/y5825e/y5 825e00.pdf

Coppinger, R., \& Coppinger, L. (2002). Dogs: A new understanding of canine origin, behaviour and evolution. Chicago, IL: University of Chicago Press.

Davis, B. W., Alie, K., W., Fielding, W. J., Morters, M., \& Galindo, F. (2007).

Preliminary observations on the characteristics of the owned dog population in Roseau, Dominica. Journal of Applied Animal Welfare Science, 10(2), 141-151.

doi.org/10.1080/10888700701313520

Fielding, W. J. (2007). Knowledge of the welfare of non-human animals and prevalence of dog care practices in New Providence, The Bahamas. Journal of Applied Animal Welfare Science, 10(2), 153-168. doi.org/10.1080/10888700701313587

Fielding, W. J. (2010). Determinants of the level of care provided for various types and sizes of dogs in New Providence, The Bahamas. The International Journal of Bahamian Studies, 16, 63-77. Retrieved from http://journals.sfu.ca/cob /index.php/files/article/view/119/128

Fielding, W. J., Gall, M., Green, D., \& Eller, W. S. (2012). Care of dogs and attitudes of dog owners in Port-au-Prince, the Republic of Haiti. Journal of Applied Animal Welfare Science, 15, 236-53. doi.org/10.1080/10888705.2012.683760

Fielding, W. J., Mather, J., \& Isaacs, M. (2005). Potcakes: Dog ownership in New Providence, The Bahamas. Lafayette, IN: Purdue University Press.

Fielding, W. J., \& Ostberg, A. (2008). Animal welfare in the wider Caribbean in 2008, with emphasis on dogs. Retrieved from http://www.hsi.org/assets/pdfs/2008_carib bean_animal-welfare_conference/ survey_animal_welfare_organizations.pdf

Fielding, W. J., \& Plumridge, S. (2005). Characteristics of owned dogs on the island of New Providence, The Bahamas. Journal of Applied Animal Welfare Science, 8(4), 245-260. doi.org/10.1207/s15327604jaws0804_2

Food and Agriculture Organization of the United Nations. (2010). Dog population management options with special emphasis on animal welfare and health. Rome, Italy: Author. Retrieved from http://www.fao.org/ag/againfo/home/docu ments/2010_sept_econferenceDog_population.pdf

Grennan, E. H., \& Fielding, W. J. (2008). Tourists' reactions to non-human animals: Implications for tourist-animal research in the Caribbean. Retrieved from http://www.caribbeananimalwelfare.org/im 
ages/Animal_welfare_organization_survey _results_CAWC08.pdf

Humane Society International. (2002, April). Challenges of animal protection on island nations: With special emphasis on dogs and cats. Proceedings of the conference, Miami Beach, Florida. Retrieved from http://files.hsus.org/webfiles/HSI/E_Librar y_PDFs/eng_challenges_island_nations.pd f.

Inter-American Institute for Cooperation on Agriculture (2009). The agricultural, food and health challenge: Critical issues, perspectives and options. Port of Spain, Trinidad: Author. Retrieved from http://orton.catie.ac.cr/repdoc/A5356E/A53 56E.PDF

Market Solutions LLC. (2012). Caribbean market potential for U.S. pet food:

Findings of a strategic assessment. Washington, DC: Pet Food Institute.

National Research Council (U.S.) Ad Hoc Committee on Dog and Cat Nutrition. (2006). Nutrient requirements of dogs and cats. Washington, DC: National Academies Press. Retrieved from http://www.nap.edu/openbook.php?record _id $=10668$

Pet Food Institute. (2013). Pet food info.

Retreived from http://www.petfoodinstitute.org/?page=Pet FoodInfo
Tasker, L. (2007). An investigation of stray dog and cat population control practices across Europe. Retrieved from the World Society for the Protection of Animals \& RSPCA International Department website http://www.rspca.org.uk/ImageLocator/Loc ateAsset?asset $=$ document $\&$ assetId=123271 $1401369 \&$ mode $=$ prd

United Nations Statistics Division. (2012). National accounts main aggregates. Retrieved from http://unstats.un.org/unsd/snaama/dnlList.a $\mathrm{sp}$

Williams, S. (2012, September 22). Dogs get cheap pig feed. The Jamaica Star Online. Retrieved from http://jamaicastar.com/thestar/20120922/news/news2.ht $\mathrm{ml}$

Worrell, D., Marshall, D., \& Smith, N. (2000). The political economy of exchange rate policy in the Caribbean. Washington, DC: Inter-American Development Bank. Retrieved from http://www.iadb.org/res/publications/pubfil es/pubr-401.pdf

Yaeger, M. J., Mullin, K., Ensley, S. M., Ware, W. A., \& Slavin, R. A. (2012). Myocardial toxicity in a group of greyhounds administered ractopamine. Veterinary Pathology, 49(3), 569-573. doi:10.1177/030098581142475 